\title{
ANALISIS DEFECT PADA PROSES STRANDING DENGAN METODE DMAIC PT. X
}

\section{DEFECT ANALYSIS ON STRANDING PROCESS USING DMAIC METHOD PT. X}

\author{
Angga Adi Pratama1, Miftahul Imtihan ${ }^{2 *}$, Suwaryo Nugroho ${ }^{3}$ \\ 1,2*3 Program Studi Teknik Industri-Sekolah Tinggi Teknologi Muhammadiyah Cileungsi, Bogor, Jawa Barat, Indonesia \\ Perum PT. SC, Jl. Anggrek No. 25, Cileungsi, Bogor, Indonesia 16820 \\ *Email: anggaadipratama6177@gmail.com11, miftahul@sttmcileungsi.ac.id2², suwaryo.nugroho@sttmcileungsi.ac.id³
}

\section{INFORMASI ARTIKEL ABSTRAK}

Histori Artikel

Artikel dikirim

$29 / 10 / 2020$

- Artikel diperbaiki

$4 / 11 / 2020$

- $\quad$ Artikel diterima

20/11/2020

- Artikel dipublish $30 / 11 / 2020$
Penerapan perencanaan produksi yang tepat akan menghasilkan produksi yang memenuhi standar kualitas dengan jumlah cacat produk (defect) yang rendah. Permasalahan yang terjadi yaitu defect pada alur proses stranding yang menjadi temuan masih terhitung tinggi. PT. X adalah perusahaan yang bergerak dalam bidang manufacture of power cable, telecommunication cable, enameled wires. Tujuan penelitian ini untuk melakukan analisis defect secara spesifik pada proses Stranding sebagai upaya meningkatkan kualitas produk kabel. Adapun metode yang digunakan adalah DMAIC (Define, Measure, Analyze, Improvement dan Control). Hasil penelitian pada tahap Define melalui diagram pareto terdapat 3 jenis defect yaitu (1).Loss 76.80\%, (2). Attenuation Big 19.20\%, (3). Loose Tube Brittle 4.00\%. Tahap Measure diperoleh nilai level sigma $3.27 \sigma$, pada tahap analyze yang menjadi faktor penyebab defect adalah material dan mesin, dan Improve yang diterapkan adalah dengan membuat Design of Experiments (DOE) yaitu dengan pemasangan keramik penghalang Filler dan memasang Dies CSM di area pay off CSM proses Stranding dan level sigma diperoleh menjadi 3,76б. Adapun tahap Control menunjukkan bahwa produk masuk dalam area batas kontrol atas dan batas kontrol atas (UCL dan LCL). Bahwa defect pada proses stranding dengan metode DMAIC setelah dilakukan improve menurun dari 625,034 meter (11.63\%) menjadi 126,050 meter (3.54\%).

Kata Kunci: Kualitas, Defect, Stranding Fiber Optic, DMAIC.

\section{ABSTRACT}

The implementation of proper production planning will result in production that meets quality standards with a low number of defects. The problem that occurs is defects in the stranding process flow which are still relatively high findings. PT. $X$ is a company engaged in the manufacture of power cables, telecommunication 
cables, enameled wires. The purpose of this research is to conduct a defect analysis specifically in the stranding process as an effort to improve the quality of cable products. The method used is DMAIC (Define, Measure, Analyze, Improvement, and Control). The results of the research at the Define stage through the Pareto diagram, there were 3 types of defects, namely (1). Loss 76.80\%, (2). Attenuation Big 19.20\%, (3). Loose Tube Brittle 4.00\%. In the Measure stage, the sigma level value is 3.27 , at the analysis stage the factors causing the defect are material and machines and the Improve applied is by making Design of Experiments (DOE), namely by installing Filler barrier ceramics and installing CSM Dies in the CSM pay off area of the process. The stranding and the sigma level are obtained to be 3,766. The Control stage shows that the product falls within the upper control and upper control limits (UCL and LCL). That the defect in the stranding process using the DMAIC method after improving it decreased from 625,034 meters (11.63\%) to 126,050 meters (3.54\%).

Keywords: Quality, Defect, Fiber Optic Stranding, Dmaic

\section{Pendahuluan}

Penerapan perencanaan produksi yang tepat menghasilkan produksi yang sesuai harapan, yaitu terpenuhinya standar kualitas dengan jumlah cacat produk (defect) yang rendah. Permasalahan yang terjadi yaitu defect pada alur proses stranding yang menjadi temuan masih terhitung tinggi. Salah satu kunci sukses memenangkan persaingan industri dengan terpenuhinya kualitas agar terjaga sustainability sehingga perusahaan menjaga jumlah defect pada proses stranding agar dapat diminimalisir.

PT. X adalah perusahaan yang bergerak dalam bidang manufacture of power cable, telecommunication cable, enameled wires. Tingginya defect pada proses stranding yang ditemukan periode Januari-April tahun 2020 yaitu 625,034 meter dari total produksi 5,373,349 meter. Penelitian yang berbeda, Six Sigma DMAIC dapat dianggap sebagai panduan untuk pemecahan masalah dan perbaikan produk atau proses, mayoritas perusahaan mulai menerapkan Six Sigma menggunakan metodologi DMAIC [1]. Untuk penyebab defect dari cocacola $1000 \mathrm{ml}$ terdiri atas cap cacat, cap quality cacat, serta underfill cacat dengan proporsi terbesar terjadi pada keadaan underfill dengan persentase $61,21 \%$, diikuti dengan cap cacat 22,97\%, dan cap quality cacat 15,82 .[2]. Melalui strategi DMAIC pada tahapan Improve dengan melakukan Redesign alat tambahan yaitu Install Clamp Welding Jig, maka produk yang dihasilkan mampu meningkat kualitasnya sesuai yang diinginkan pelanggan. Indikator nilai sigma level meningkat dari 3,14 $\sigma$ menjadi 4,32 $\sigma .[3]$. Hasil penelitian bahwa kapabilitas dan nilai sigma kinerja perusahaan dalam peningkatan kualitas produk sebesar 7560 DPMO dengan nilai sigma 3,93 [4]. Proses implementasi DMAIC dari metodologi Six Sigma, dikombinasikan dengan Value Engineering (VE). Dan pada tahap perbaikannya menggunakan metode percobaan ortogonal DOE untuk mengurangi jumlah percobaan, biaya percobaan, dan meningkatkan tingkat manajemen mutu serta daya saing inti perusahaan [5]. 


\subsection{Definisi kualitas}

Secara konvensional, kualitas didefinisikan dengan penggambaran karakteristik langsung dari suatu produk, seperti performansi, keandalan, kemudahan dalam penggunaan, estetika dan sebagainya [6]. Secara strategi kualitas didefinisikan sebagai segala sesuatu yang mampu memenuhi keinginan atau kebutuhan pelanggan (meeting the needs of customers). Keunggulan suatu produk terukur melalui tingkat kepuasan pelanggan [7]. Sistem Manajemen Mutu merupakan sekumpulan prosedur terdokumentasi dan praktek-praktek standar untuk manajemen sistem yang bertujuan menjamin kesesuaian dari suatu proses dan produk (barangjasa) terhadap kebutuhan atau persyaratan itu ditentukan atau dispesifikasikan oleh pelanggan atau organisasi [8]. Implementasi metode pengendalian kualitas mampu memberikan informasi tentang berbagai macam perbaikan yang dapat dilakukan oleh perusahaan dalam rangka meningkatkan kualitas produk yang dihasilkan [9].

\subsection{Six sigma}

Penelitian Six-sigma DMAIC ini diawali dengan identifikasi masalah melalui voice of customer pada tahap define. Langkah selanjutnya mengumpulkan data spesifikasi manik ban yang ada. Langkah ini diikuti oleh langkah-langkah analisis dan perbaikan, di mana alat kualitas enam-sigma seperti diagram sebab-akibat, kontrol proses statistik, dan analisis substansial dari sistem yang ada diimplementasikan untuk identifikasi akar penyebab dan pengurangan variasi proses [10]. Metode Lean Six Sigma merupakan metode yang berfokus pada bebas kesalahan (zero defect) dan mengurangi variasi serta mempercepat penghapusan pemborosan di seluruh value stream yang akan memberikan nilai tambah [11].

Berdasarkan teori Six Sigma, hanya terdapat 3, 4 cacat per sejuta kesempatan pada proses produksi. Semakin tinggi target sigma yang dicapai maka kinerja sistem industri semakin membaik [12]. Sementara metodologi inti Six Sigma, yang terdiri dari lima tahap, yaitu mendefinisikan, mengukur, menganalisis, meningkatkan, dan mengendalikan DMAIC [13].

Struktur yang muncul untuk manajemen kualitas ini membantu organisasi mengontrol aktivitas peningkatan proses dengan lebih ketat, sementara pada saat yang sama menciptakan konteks yang memungkinkan eksplorasi masalah antara anggota organisasi yang berbeda [14]. Hasilnya ada perbedaan model dalam kaitannya dengan pentingnya area keputusan dan kinerja yang dicapai dalam prioritas kompetitif. Secara individual, lean manufacturing, LSS memiliki tingkat kepentingan yang berbeda-beda dalam bidang keputusan fasilitas, integrasi vertikal, dan perencanaan produksi dan kontrol. Dimensi kinerja dengan kinerja terbaik adalah kecepatan, kualitas, keandalan, dan biaya [15].

Strategi manajemen proyek untuk memenuhi tujuan proyek Six Sigma tepat waktu dan sesuai anggaran perencana proyek Six Sigma menunjukkan Six Sigma Black Belts dan Green Belts bagaimana menggunakan manajemen proyek alat untuk menyelesaikan peningkatan Six Sigma tepat waktu dan sesuai anggaran. Perencana menyediakan lusinan alat manajemen proyek yang dapat direproduksi untuk mengikuti format perbaikan proses Define-Measure-Analyze-ImproveControl (DMAIC) [16].

\section{Metode}

Metode pengumpulan data terkait penelitian yang dilakukan pada proses stranding dengan metode DMAIC.

a) Metode literatur; proses pengambilan data terkait dengan permasalahan dalam penelitian melalui buku-buku literatur (kepustakaan), materi-materi di internet, jurnal- 
jurnal penelitian, dan lainnya sehingga data yang dimaksud memiliki dasar teori yang memadai dan relevan.

b) Metode observasi; proses pengambilan data yang dilakukan pengamatan secara langsung dengan berkunjung dan survei ke lokasi penelitian.

c) Metode interview; proses mendapatkan data melalui diskusi dari sumber yang valid terkait kegiatan proses stranding, juga diskusi dengan ahli dari alat yang dioperasikan.

\section{Hasil dan Pembahasan}

\subsection{Tahap define}

Pada tahap define diperoleh defect pada proses stranding dengan jenis defect yaitu (1) Attenuation Big, (2) Loss, (3) Loose Tube Brittle.

Tabel 1. Produksi dan jenis defect proses stranding

\begin{tabular}{|c|c|c|c|c|c|}
\hline \multirow[b]{2}{*}{ Bulan } & \multirow[b]{2}{*}{ Jumlah Produksi (meter) } & \multicolumn{3}{|c|}{ Jenis Defect (meter) } & \multirow{2}{*}{$\begin{array}{c}\text { Jumlah Defect } \\
\text { (meter) }\end{array}$} \\
\hline & & $\begin{array}{c}\text { Attenuation } \\
\text { Big }\end{array}$ & Loss & $\begin{array}{l}\text { Loose Tube } \\
\text { Brittle }\end{array}$ & \\
\hline Januari & $1,686,872$ & 20,000 & 114,000 & 15,034 & 149,034 \\
\hline Februari & $1,233,460$ & 25,000 & 130,000 & - & 155,000 \\
\hline Maret & $1,702,002$ & 30,000 & 124,000 & 10,000 & 164,000 \\
\hline April & 751,015 & 45,000 & 112,000 & - & 157,000 \\
\hline Jumlah & $5,373,349$ & 120,000 & 480,000 & 25,034 & 625,034 \\
\hline
\end{tabular}

Attenuation Big nilai hasil redaman dari fiber optic, sedangkan loss putusnya hasil redaman dari fiber optic yang berada di dalam loose tube, dan Loose Tube Brittle rapuhnya pelapis pada fiber optic yang diakibatkan kurang tepatnya set-up mesin extruder.

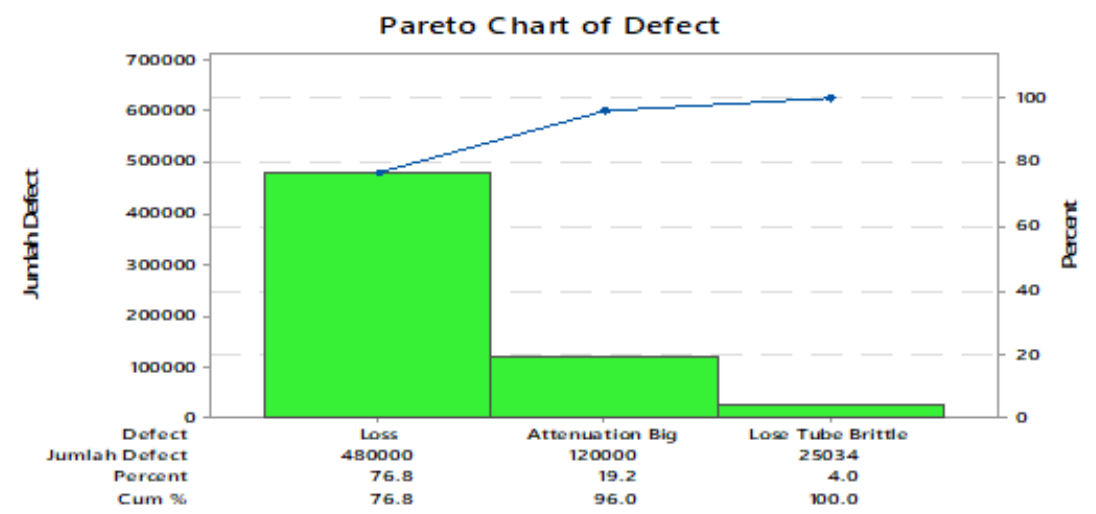

Gambar 1. Diagram Pareto defect proses stranding

Pada gambar 1 menunjukkan jumlah defect tertinggi jenis defect loss dengan jumlah 480.000 meter yang berarti secara akumulasi persentase mencapai angka $76.80 \%$.

\subsection{Tahap measure}

A. Perhitungan DPU (Defect per-Unit)

$$
\begin{aligned}
& \text { DPU }=\frac{\text { Jumlah produk cacat }}{\text { Jumlah produk yang diinspeksi }} \\
& \text { DPU }=\frac{625,034}{5,373,349}=0.116321
\end{aligned}
$$


B. Perhitungan TOP (Total Opportunities)

TOP = Jumlah Produksi $x$ CTQ

TOP $=5,373,349 \times 3$

TOP $=16,120,047$

C. Perhitungan DPO (Defect Per Opportunities)

DPO $=$ Jumlah Cacat $/$ TOP

DPO $=625,034 / 16,120,047$

$\mathrm{DPO}=0.038774$

D. Perhitungan DPMO (Defect per Million Opportunity)

$\mathrm{DPMO}=\mathrm{DPO} \times 1.000 .000$

$\mathrm{DPMO}=0,038774 \times 1.000 .000$

DPMO $=38,774$

E. Perhitungan Nilai Six Sigma

Sigma $=$ NORM.S.INV $((1.000 .000-$ DPMO $) / 1.000 .000)+1.5$

Sigma $=$ NORM.S.INV $((1.000 .000-38,774) / 1.000 .000)+1.5$

Sigma $=3.27 \sigma$

\subsection{Tahap analyze}

Tahap analyze dilakukan untuk mengetahui faktor-faktor sebab dan akibat terjadinya defect loss pada proses stranding dengan menggunakan diagram fishbone.

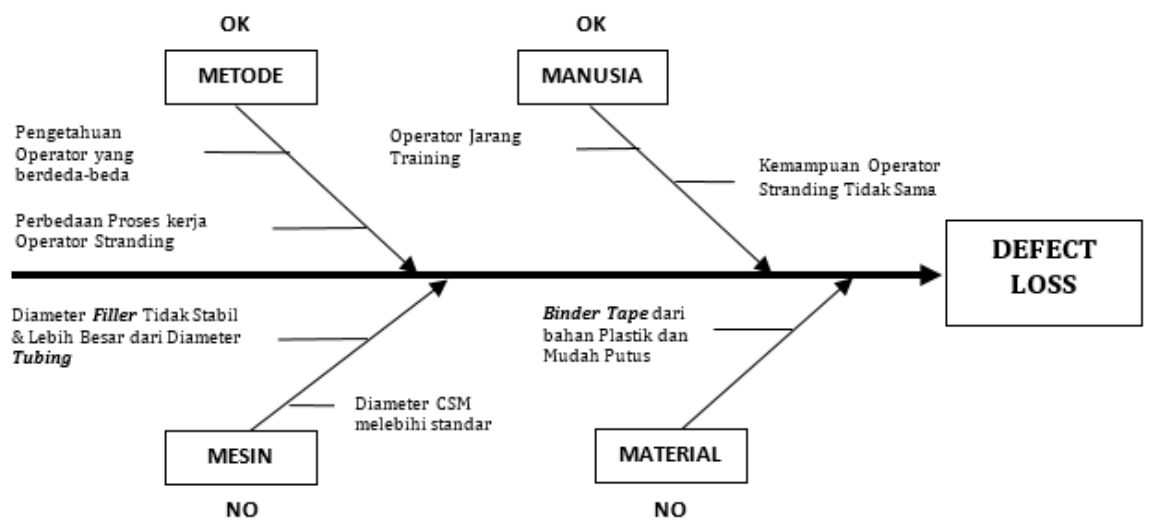

Gambar 2. Diagram fishbone jenis defect loss

Tabel 2 hasil pengamatan diagram fishbone pada gambar 2 terdapat jenis Defect Loss pada proses stranding.

Tabel 2. Hasil pengamatan diagram fishbone-defect loss

\begin{tabular}{cclc}
\hline No & Faktor & \multicolumn{1}{c}{ Kondisi yang terjadi } & Status \\
\hline 1 & Manusia & $\begin{array}{l}\text { a. Kemampuan operator tidak merata. } \\
\text { b. Perbedaan lama bekerja. }\end{array}$ & Ok \\
2 & Metode & $\begin{array}{l}\text { a. Perbedaan pengetahuan operator; } \\
\text { b. Proses stranding kurang tepat. } \\
\text { a. Binder tape berbahan dasar plastik dan mudah putus; } \\
\text { b. Pilinan hasil stranding kendur. } \\
\text { Material }\end{array}$ & Ok \\
& \multirow{2}{*}{ Mesin } & $\begin{array}{l}\text { a. Diameter filler tidak stabil dan lebih besar dari diameter } \\
\text { b. Diameter CSM (Central Strength Member) melebihi standar. }\end{array}$ & No \\
& &
\end{tabular}


Pada tabel 2 memberikan gambaran faktor sebab akibat terjadinya Defect Loss proses stranding kabel optik yaitu pada material dan mesin. Hal ini diketahui bahwa material Binder Tape berbahan plastik sehingga mudah putus, sehingga mengakibatkan pilinan hasil stranding menjadi kendur. Untuk mesin dengan Diameter Filler tidak stabil dan lebih besar dari diameter Tubing dan diameter CSM melebihi standar sehingga tubing dalam proses stranding menjadi terjepit dan menyebabkan tubing di dalam pilinan stranding menjadi loss. Dengan hasil pengamatan yang menjadi temuan, maka improving continuous dengan melakukan Design of Experiments dengan memasang keramik penghalang filler dan memasang dies CSM di area pay off CSM stranding.

\subsection{Tahap improve}

Untuk tahap penerapan improve terhadap defect loss proses stranding pada pembuatan fiber optik secara Design of Experiments yaitu dengan memasang keramik penghalang filler dan memasang Dies CSM di area pay off CSM stranding.
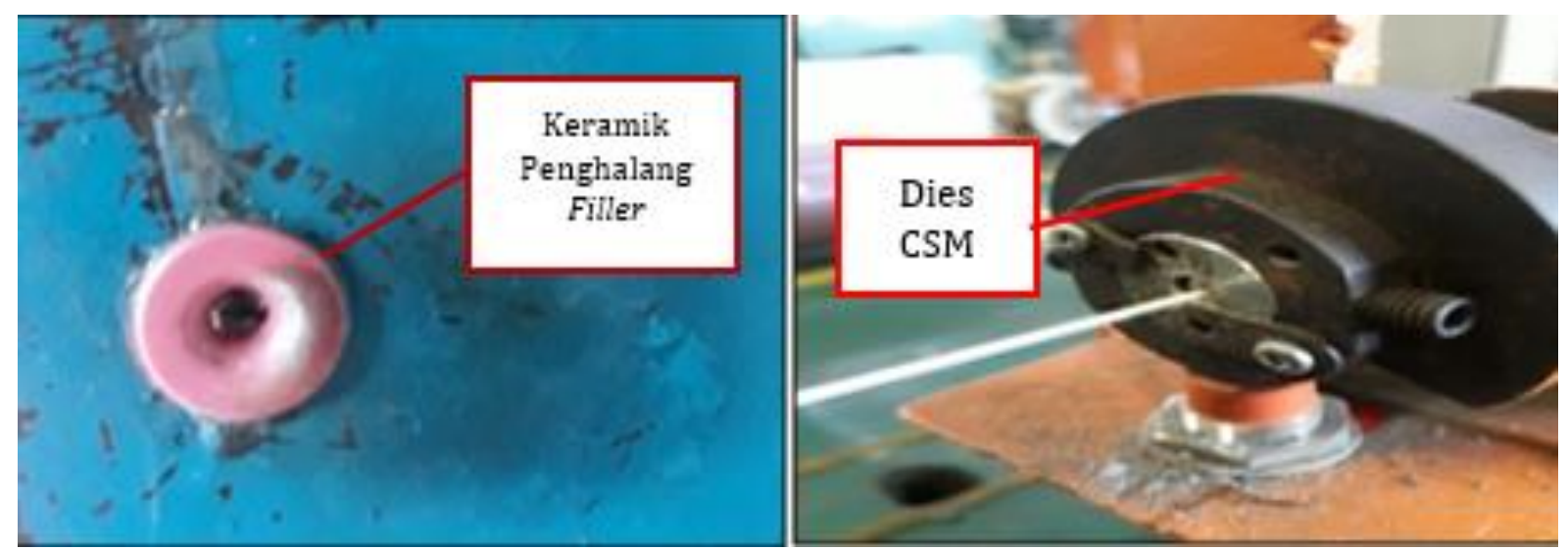

Gambar 3. DOE pemasangan keramik penghalang filler dan dies CSM.

Pada gambar 3 tubing dipasang keramik penghalang filler. Jika diameter filler melebihi spesifikasi atau filler berubah bentuk maka filler putus di tubing dan tidak sampai ke proses stranding. Dengan ini Defect Loss pada proses stranding bisa diminimalisir atau diturunkan. Dengan memasang dies CSM di area pay off CSM di mesin stranding maka CSM dengan diameter melebihi standar maka menyentuh sensor yang ada pada dies tersebut. Jika itu terjadi mesin stranding otomatis berhenti, sehingga CSM dengan diameter melebihi standar tidak masuk ke dalam mesin stranding.

Hasil tahapan improve dengan memasang keramik penghalang Filler dan memasang Dies CSM di area pay off CSM (Central Strength Member) stranding ternyata berhasil. Terbukti hal tersebut mampu menurunkan defect pada proses stranding dari 625,034 meter atau $11.63 \%$ menjadi 126.050 meter atau 3.54\%.

\subsection{Tahap kontrol}

Grafik statistical processing control sebelum dilakukan Improve, terhadap jumlah produk fiber optik dan terlihat masih terdapat data yang di luar batas kendali atas (UCL) yang dijelaskan pada gambar 4.

Pada tabel 3 data produksi dan jenis defect proses stranding setelah improve periode bulan Mei-Juni tahun 2020. 
Tabel 3. Produksi dan jenis defect proses stranding setelah improve

\begin{tabular}{cccccc}
\hline Bulan & $\begin{array}{c}\text { Jumlah } \\
\text { Produksi } \\
\text { (meter) }\end{array}$ & $\begin{array}{c}\text { Attenuation } \\
\text { Big }\end{array}$ & Loss & $\begin{array}{c}\text { Loose } \\
\text { Tube } \\
\text { Brittle }\end{array}$ & $\begin{array}{c}\text { Jumlah } \\
\text { Defect } \\
\text { (meter) }\end{array}$ \\
\hline M e i & $1,900,767$ & 17,500 & 39,350 & 12,500 & 69,350 \\
Juni & $1,658,000$ & 19,500 & 32,700 & 4500 & 56,700 \\
\hline JUMLAH & $3,558,767$ & 37,000 & 72,050 & 17,000 & 126,050 \\
\hline
\end{tabular}

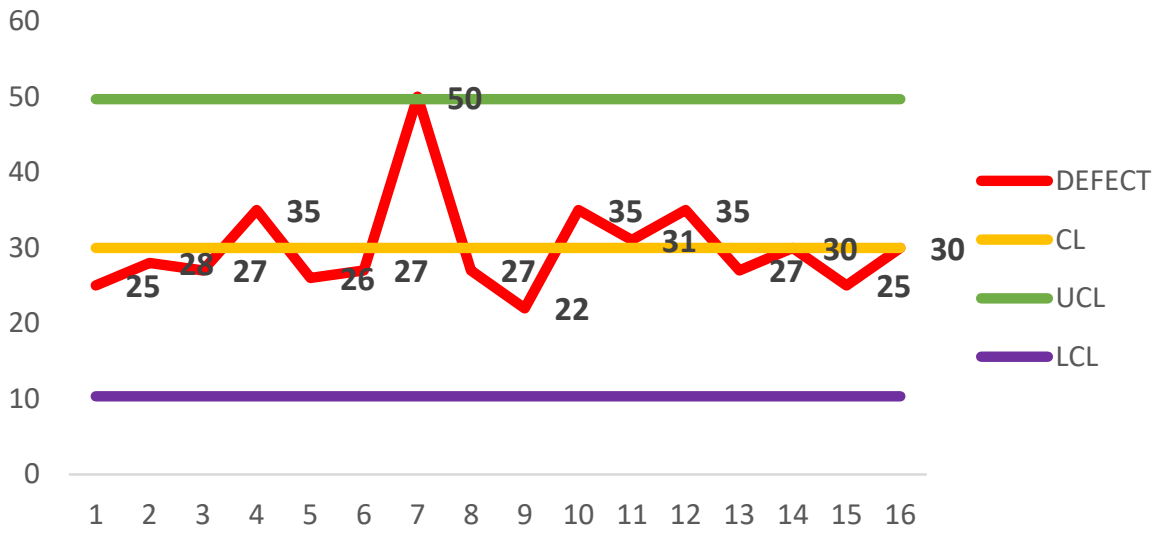

Gambar 4. SPC Defect sebelum improve

Perhitungan sigma level setelah dilakukan improve.

1) DPU (Defect Per Unit).

$$
\mathrm{DPU}=\frac{126,050}{3,558,767}=0,035419
$$

2) Total Opportunity.

TOP $=3,558,767 \times 3$

TOP $=10,676,301$

3) DPO (Defect Per Opportunity).

DPO $=\frac{126,050}{10,676,301}$

DPO $=0.011806$

4) DPMO (Defect Per Million Opportunity).

$\mathrm{DPMO}=\mathrm{DPO} \times 1.000 .000$

DPMO $=0,011806 \times 1.000 .000$

DPMO $=11,806$

5) Menghitung nilai Six Sigma

NORM.S.INV((1.000.000 - DPMO) / 1.000.000) + 1.5

NORM.S.INV((1.000.000-11,806) / 1.000.000 +1.5

Sigma $=3.76 \sigma$ 


\section{Sigma Level}

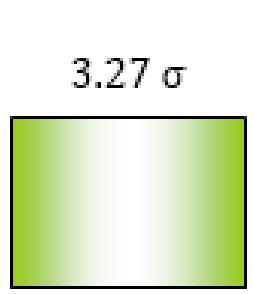

Sebelum
$3.76 \sigma$

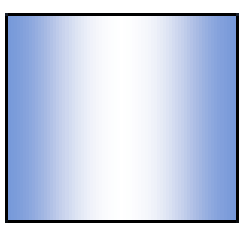

Sesudah

Gambar 5. Sigma level sebelum-sesudah improve

Dengan melakukan improve yang menerapkan metode memasang keramik penghalang Filler dan Dies CSM, terlihat pada gambar 5 menunjukkan indikator peningkatan level sigma dari nilai $3.27 \sigma$ menjadi $3.76 \sigma$. Hal ini menunjukkan bahwa defect pada proses stranding dengan metode DMAIC menurun secara signifikan dari 625,034 meter (11.63 \%) menjadi 126,050 meter $(3.54 \%)$.

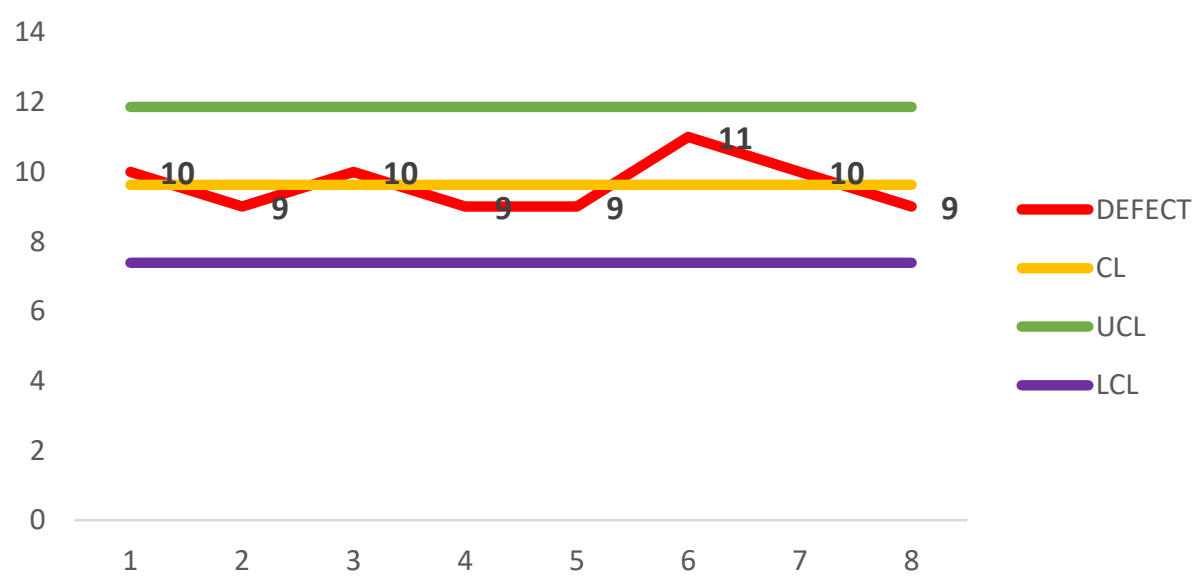

Gambar 6. SPC defect setelah improve

Hal ini juga dapat diperlihatkan pada gambar 6 SPC setelah improve menunjukkan bahwa produk fiber optik masuk pada area Upper Control Limit (UCL) dan Low Control Limit (LCL).

\section{Simpulan}

Berdasarkan pengolahan data dengan metode Define, Measure, Analyze, Improve, Control, maka terdapat peningkatan level sigma dari 3.27 $\sigma$ menjadi $3.76 \sigma$ sehingga terjadi penurunan defect pada proses Stranding secara signifikan dari 625,034 meter (11.63\%) menjadi 126,050 meter (3.54\%).

\section{Ucapan Terima Kasih}

Ucapan Terima Kasih tak terhingga kepada seluruh kolega yang telah mendukung dalam proses pengambilan data, penyusunan hasil penelitian sampai dengan publikasi jurnal. Semoga jurnal ini bermanfaat bagi seluruh pihak yang membutuhkannya.

\section{Reference}

[1] R. Godina, J. C. O. Matias, dan S. G. Azevedo, "Quality improvement with statistical process 
control in the automotive industry," Int. J. Ind. Eng. Manag., 2016.

[2] P. A. Wicaksono, D. P. Sari, N. U. Handayani, dan H. Prastawa, "PENINGKATAN PENGENDALIAN KUALITAS MELALUI METODE LEAN SIX SIGMA,” J@ti Undip J. Tek. Ind., 2017, doi: 10.14710/jati.12.3.205-212.

[3] M. Imtihan dan R. Revino, "REDESIGN ALAT TAMBAHAN PADA MESIN PRODUKSI KOMPONEN OTOMOTIF BODY INNER DALAM MENINGKATKAN KUALITAS MELALUI STRATEGI DMAIC," J. Ind. Eng. Manag., 2017, doi: 10.33536/jiem.v2i2.153.

[4] S. Supriyadi, G. Ramayanti, dan A. Chandra Roberto, "Analisis Kualitas Produk dengan Pendekatan Six Sigma," in Prosiding SNTI dan SATELIT 20171 (Teknik Industri Universitas Brawijaya ), 2017, doi: DOI 10.17605/OSF.IO/UVPEZ.

[5] H. Jiang dan Y. Cao, "Research on enterprise quality innovation of VE and DMAIC tool integrated application," in Proceedings - 2020 International Conference on E-Commerce and Internet Technology, ECIT 2020, 2020, doi: 10.1109/ECIT50008.2020.00092.

[6] W. Ariani, "Manajemen Kualitas," J. Manag., 2016.

[7] M. A. Fauzi, “Manajemen kualitas," J. Manag., 2013.

[8] V. Gasperz, "ISO 9001: 2000 and Contunial Quality Improvement, PT," Gramedia Pustaka Utama, Jakarta, 2002.

[9] H. Tannady, "Pengendalian Kualitas," Sleman: Graha Ilmu. 2015.

[10] V. Gupta, R. Jain, M. L. Meena, dan G. S. Dangayach, "Six-sigma application in tiremanufacturing company: a case study," J. Ind. Eng. Int., 2018, doi: 10.1007/s40092-0170234-6.

[11] Y. Iriani, "Usulan Peningkatan Kualitas Pelayanan Pelanggan dengan Menggunakan Integrasi Metode Servqual , Lean dan Six Sigma (Studi Kasus di PT ." X " Bandung)," Pros. Semin. Nas. Tek. Dan Manaj. Ind., 2011.

[12] A. M. Dewi dan N. B. Puspitasari, "Analisis Pengendalian Kualitas Menggunakan Metode Six Sigma pada Produk AMDK 240 Ml PT. Tirta Investama Klaten," Ind. Eng. Online J., 2019.

[13] F. Tsung, "Six Sigma," in Springer Handbooks, 2006.

[14] R. G. Schroeder, K. Linderman, C. Liedtke, dan A. S. Choo, "Six Sigma: Definition and underlying theory," J. Oper. Manag., 2008, doi: 10.1016/j.jom.2007.06.007.

[15] E. Drohomeretski, S. E. Gouvea Da Costa, E. Pinheiro De Lima, dan P. A. D. R. Garbuio, "Lean, six sigma and lean six sigma: An analysis based on operations strategy," Int. J. Prod. Res., 2014, doi: 10.1080/00207543.2013.842015.

[16] T. Pyzdek, The Six Sigma Project Planner. 2003. 